\title{
Preparation of gold in Y-type zeolite for carbon monoxide oxidation
}

\author{
Yih-Ming Kang, Ben-Zu Wan * \\ Department of Chemical Engineering, National Taiwan University, Taipei, Taiwan, R.O.C. \\ Received 15 August 1994; revised 23 December 1994; accepted 16 March 1995
}

\begin{abstract}
Gold Y-type zeolite catalysts were prepared by adding Y-type zeolite to a stirred aqueous solution of chloroauric acid. It was demonstrated that the ion-exchange process between gold ions and the zeolite dominated the preparation of gold into Y-type zeolite. The exchanged gold/Y catalysts possessed high catalytic activities for low-temperature carbon monoxide oxidation without any pretreatment. The activity could be promoted by addition of sodium hydroxide to the preparation solution. Promotion was attributed to the substitution of $\mathrm{OH}^{-}$for the chloride around the gold ions. During the activity test, these gold catalysts were deactivated as a result of the transformation of active gold(III) species into gold metal of poor activity.

Keywords: Carbon monoxide oxidation; Gold; Ion exchange; Zeolite
\end{abstract}

\section{Introduction}

The removal of carbon monoxide is an important subject in environmental protection. Several catalysts, such as gold mixed with cobalt oxide, iron oxide, etc., have been found to be effective for the oxidation of carbon monoxide at temperatures as low as $203 \mathrm{~K}$ and are moisture tolerant [1,2]. However, the coprecipitation method used for the preparation produced catalysts of low surface area, and a significant amount of gold was buried within the catalyst particles and was not available for reaction. Haruta et al. [3] reported an improved preparation technique that supported gold and iron oxide on high surface area alumina and honeycomb carrier.

Because the high activities of coprecipitated gold catalysts were attributed to the formation of ultrafine gold particles smaller than $10 \mathrm{~nm}$ and stabilized by host metal

* Corresponding author. Fax. $(+886-2) 3623040$. 
oxide $[3,4]$, several researchers investigated the preparation of gold clusters. The preparation of hydrosols of gold clusters down to $2 \mathrm{~nm}$ are reportedly formed by photoreduction of $\mathrm{AuCl}_{4}^{-}$-cationic surfactant complexes [5] and by reduction of gold( III) ions with tetrakis (hydroxymethyl) phosphonium chloride [6]. $\mathrm{A} \mathrm{AuCl}_{3}$ / $\mathrm{NaY}$ sample prepared by spontaneous monolayer-dispersion of $\mathrm{AuCl}_{3}$ with $\mathrm{NaY}$ zeolite powder has also been reported [7]. The $\mathrm{AuCl}_{3}$ was said to be in the zeolite pores as a monolayer or highly dispersed. In addition, $\mathrm{Au}$ fine particles were dispersed on ferrite films of $\mathrm{Fe}_{3} \mathrm{O}_{4}$ or $\alpha-\mathrm{Fe}_{2} \mathrm{O}_{3}$ by ferrite plating in an aqueous solution below $100^{\circ} \mathrm{C}[8]$.

The most commonly practiced techniques for preparing supported catalysts are incipient wetness impregnation and ion exchange. In the latter, the interaction between the deposited salt and the support is stronger than that in the former. Consequently, the exchanged sample can achieve much higher metal dispersion and more homogeneous metal distribution than the impregnated sample [9]. Thus, in the present study, ion exchange was used to prepare gold into exchangeable $\mathrm{Y}$ type zeolite.

\section{Experimental}

$\mathrm{Y}$-type zeolite with $\mathrm{Si} / \mathrm{Al}=2.28$, sodium loading $=3.42 \mathrm{wt} . \%$ (designated $\mathrm{Y} 1$ ) and with $\mathrm{Si} / \mathrm{Al}=28.7$, sodium loading $=0.72 \mathrm{wt}$. $\%$ (designated $\mathrm{Y} 2$ ) from Conteka were used as supports in this research. According to the characterization report provided by Conteka, the unit cell sizes and the BET surface areas were $24.50 \AA$ and $730 \mathrm{~m}^{2} / \mathrm{g}$ of $\mathrm{Y} 1$, and $24.25 \AA$ and $720 \mathrm{~m}^{2} / \mathrm{g}$ of $\mathrm{Y} 2$. Therefore, the change in the number of exchange sites is the only significant difference between the two zeolites. Ion exchange was used for the preparation of gold in Y-type zeolite, and the procedures were as follows: $0.25 \mathrm{~g}$ of chloroauric acid $\left(\mathrm{HAuCl}_{4} \cdot 3 \mathrm{H}_{2} \mathrm{O}\right.$, Merck) was dissolved in $500 \mathrm{~cm}^{3}$ of deionized water. Sodium hydroxide (0.06-0.16 g) was used to adjust the $\mathrm{pH}$ of the solution. After stirring for $1 \mathrm{~h}, 5 \mathrm{~g}$ of $\mathrm{Y}$-type zeolite was added, then the solution was heated to $353 \mathrm{~K}$ and maintained at this temperature for $16 \mathrm{~h}$. The exchanged gold/Y samples (Au-13/Y1, Au-16/Y1, Au-10/Y1 and $\mathrm{Au}-16 / \mathrm{Y} 2$ ) were obtained after filtration, and were washed until free from $\mathrm{Cl}^{-}$ ions, as detected by a $\mathrm{AgNO}_{3}$ solution. They were then dried at $333 \mathrm{~K}$ for $6 \mathrm{~h}$ under air. A reference sample, $\mathrm{HAuCl}_{4} / \mathrm{Y} 1$, for $\mathrm{X}$-ray photoelectron spectroscopy (XPS) and temperature-programmed reduction (TPR) analysis was prepared by incipient wetness impregnation of Y1 with an aqueous solution of chloroauric acid, and then dried under the same conditions as above. The $\mathrm{pH}$ of the gold solution used for the incipient wetness impregnation was lower than 2.7, and consequently $\mathrm{AuCl}_{4}^{-}$anion has its initial form in the solution. Thus, it is considered that gold would not be exchanged onto the cation exchange sites of Y-type zeolite when the incipient wetness technique was used. $\mathrm{HAuCl}_{4} / \mathrm{Y} 1$ contained 0.94 wt.- $\%$ of $\mathrm{Au}$. 
Table 1

Solution $\mathrm{pH}$ during preparation and gold loadings of the catalysts

\begin{tabular}{llcccc}
\hline Catalyst & \multicolumn{2}{l}{ Preparation solution } & & Au loadings & $d^{\mathrm{d}}$ \\
\cline { 2 - 5 } & $\mathrm{NaOH}^{\mathrm{a}}(\mathrm{g})$ & $\mathrm{pHI}^{\mathrm{b}}$ & $\mathrm{pH} 2^{\mathrm{c}}$ & $(\mathrm{wt}$. \% $)$ & $(\mathrm{nm})$ \\
\hline $\mathrm{Au}-13 / \mathrm{Y} 1$ & 0.059 & 3.60 & 6.6 & 1.78 & 22 \\
$\mathrm{Au}-16 / \mathrm{Y} 1$ & 0.119 & 6.56 & 6.7 & 1.59 & 31 \\
$\mathrm{Au}-10 / \mathrm{Y} 1$ & 0.159 & 10.80 & 6.8 & 1.24 & 39 \\
$\mathrm{Au}-16 / \mathrm{Y} 2$ & 0.119 & 6.6 & 6.4 & 0.26 & 10 \\
\hline
\end{tabular}

${ }^{a}$ The amount of $\mathrm{NaOH}$ was added into the chloroauric acid solution.

${ }^{\mathrm{h}} \mathrm{pH}$ of solution right before $\mathrm{Y}$-type zeolite was added into the solution.

$c \mathrm{pH}$ of filtrate.

The average diameter of gold species measured by TEM.

The elemental content in each sample was determined by a GBC 906 atomic absorption unit. The average diameter of the particles on the outer surface of the samples was measured using a Hitachi $\mathrm{H} 7100$ electron microscope operated at 75 $\mathrm{kV}$. The average particle diameter was determined by measuring over 100 individual particles on at least 25 sections of a TEM photograph. The experimental procedures and the apparatus for temperature-programmed reduction (TPR) were described in detail before [10]. A Perkin Elmer (Model 548) ESCA spectrometer, using $\mathrm{Mg} \mathrm{K} \alpha$ monochromatic $\mathrm{X}$-rays and equipped with a charge-compensating electron gun, was used for the investigation. The analyses of ESCA spectra were carried out at room temperature. All measured binding energies ( $\mathrm{BE}$ ) were referred to the $\mathrm{C} 1 \mathrm{~s}$ line at $284.6 \mathrm{eV}$.

Carbon monoxide oxidation was carried out in a quartz tube reactor at $303 \mathrm{~K}$ under atmospheric pressure. The catalysts which contained $0.00162 \mathrm{~g}$ of gold were directly used without any pretreatment. During the reaction, $32.67 \mathrm{~cm}^{3} / \mathrm{min}$ of air and $0.33 \mathrm{~cm}^{3} / \mathrm{min}$ of carbon monoxide were mixed before the inlet of the reactor.

\section{Results and discussion}

\subsection{Loading process of gold into Y-type zeolite}

Table 1 shows that the amount of gold prepared in $\mathrm{Y} 1$ decreased with the increase of the amount of sodium hydroxide added to the preparation solution, although the $\mathrm{pH}$ of each solution was in close range at the final stage of the preparation. It appears that the amount of gold prepared in this zeolite was a function of solution $\mathrm{pH}$ at the time when Y-type zeolite was added to the solution.

When $0.25 \mathrm{~g}$ of chloroauric acid dissolves alone in $500 \mathrm{~cm}^{3}$ of deionized water, the $\mathrm{pH}$ of this gold solution is 2.7. If $\mathrm{AuCl}_{4}^{-}$anion has its original form in this aqueous solution, gold cannot be exchanged onto the cation exchange sites of the zeolite and will be removed by washing. However, it was reported [11-13] that 
various complexes, i.e. $\mathrm{AuCl}_{3}\left(\mathrm{H}_{2} \mathrm{O}\right), \mathrm{AuCl}_{2}\left(\mathrm{H}_{2} \mathrm{O}\right) \mathrm{OH}, \mathrm{AuCl}_{3}(\mathrm{OH})^{-}$, $\mathrm{AuCl}_{2}(\mathrm{OH})_{2}^{-}, \mathrm{AuCl}(\mathrm{OH})_{3}^{-}$and $\mathrm{Au}(\mathrm{OH})_{4}^{-}$were formed as the $\mathrm{pH}$ was increased. Moreover, a zero-charged complex - $\mathrm{Au}(\mathrm{en}){ }_{2} \mathrm{Cl}_{3}$ (en = ethylene diamine), similar to the first two above, had been prepared into silica gel [14] and Y-type zeolite [15]. Presumably, the gold cations from $\mathrm{Au}(\mathrm{en})_{2} \mathrm{Cl}_{3}$ played the major role in the exchange process during preparations. In the present study, because the $\mathrm{pH}$ of the gold solution was higher than that of a pure chloroauric acid solution, it is possible that gold cations from gold hydroxide complexes were loaded into Y-type zeolite by a cation exchange process. In order to confirm this, the effect of the number of ion-exchange sites on the preparation of gold in Y-type zeolite was investigated. Another Y-type zeolite with a higher $\mathrm{Si} / \mathrm{Al}$ ratio of 28.7 and a lower sodium loading of 0.72 wt. $\%$ (designated $\mathrm{Y} 2$ ) than $\mathrm{Y} 1$ was used to prepare $\mathrm{Au}-16 / \mathrm{Y} 2$. The preparation procedures were the same as those of Au-16/Y1. It can be observed in Table 1 that the gold loading on Au-16/Y1 was more than 6 times that on Au-16/ Y2, while the number of exchange sites of $Y 1$ was more than 11 times that of $Y 2$ (based on $\mathrm{Si} / \mathrm{Al}$ ratios). This indicates that the cation exchange sites have a strong influence on the preparation of gold compounds into Y-type zeolite, and that cation exchange may be the major process during preparation. Moreover, two amorphous materials - silica alumina with $\mathrm{Si} / \mathrm{Al}=5.0$ (Davison) and silica gel (Merck) were used as supports in our recent work [16], to prepare gold catalysts. The preparation procedures were similar to those used in the present work. It was found that the amount of gold loaded onto silica alumina was more than 5 times that onto silica gel. The gold loading on Au/silica gel was less than $0.2 \mathrm{wt} . \%$. This indicates again that the presence of cation exchange sites on the supports would certainly make cation exchange dominate the gold loading process.

Although most of the gold species on Y-type zeolite is loaded by ion exchange, it should be noticed that not all of the gold species loaded were the result of ion exchange, because from TEM (also listed in Table 1), the observed gold particle sizes (more than $10 \mathrm{~nm}$ ) should not have occurred if only gold ions were in $\mathrm{Y}$ type zeolite (which consists of an array of cavities having internal diameters of only about $1.2 \mathrm{~nm}$ ) [17]. It can be observed that the average diameter of the gold particles increased with increasing sodium hydroxide addition.

Fig. 1 presents the results of TPR experiments. It can be observed that $\mathrm{Au}-13 /$ $\mathrm{Y} 1, \mathrm{Au}-16 / \mathrm{Y} 1$ and $\mathrm{Au}-10 / \mathrm{Y} 1$ showed two reduction peaks (at $125^{\circ} \mathrm{C}$ and $525^{\circ} \mathrm{C}$ ) and one shoulder (at $190^{\circ} \mathrm{C}$ ). The peak around $525^{\circ} \mathrm{C}$ can be ascribed to the reduction of gold ions which were located in sodalite cages [18], because there was no such a high-temperature reduction peak for $\mathrm{Au} / \beta$-zeolite and $\mathrm{Au} /$ mordenite [19], although they were prepared by the same procedure as Au-16/Y1. The oxidation state of gold in these three samples (Au-10/Y1, Au-16/Y1 and Au-13/ Y1) was determined by comparing the TPR areas under spectra b-d with that under spectrum a from $\mathrm{HAuCl}_{4} / \mathrm{Y} 1$. The peak areas (under the TPR spectra) per gram of gold (obtained from atomic absorption) were 4.0, 3.5 and 3.5 for Au-13/Y1, $\mathrm{Au}-16 / \mathrm{Y} 1$ and Au-10/Y1, respectively. All of them were closely equal to that of 


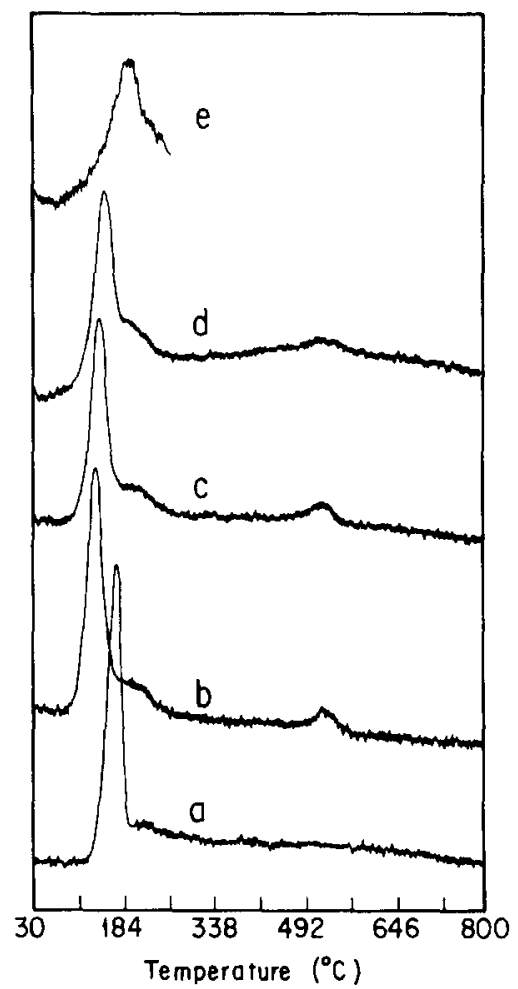

Fig. 1. TPR profiles of as-prepared catalysts which contained $0.00135 \mathrm{~g}$ of $\mathrm{Au}$. (a) $\mathrm{HAuCl}_{4} / \mathrm{Yl}$, (b) Au-13/Yl, (c) $\mathrm{Au}-16 / \mathrm{Y} 1$, (d) $\mathrm{Au}-10 / \mathrm{Y} 1$, (e) Au-16-2/Y1.

$\mathrm{HAuCl}_{4} / \mathrm{Y} 1$, which was 3.6. Therefore, the three samples all have the same oxidation state, $\mathrm{Au}^{\mathrm{III}}$, as that in $\mathrm{HAuCl}_{4} / \mathrm{Y} 1$. Furthermore, the binding energy of $\mathrm{Au} 4 \mathrm{f}_{7 / 2}$ of $\mathrm{Au}-10 / \mathrm{Y} 1(85.10 \mathrm{eV})$ obtained by XPS measurement, which was much higher than that of gold metal powder $(83.05 \mathrm{eV})$ [20] but close to that of impregnated $\mathrm{HAuCl}_{4} / \mathrm{Y} 1(84.93 \mathrm{eV})$, was another evidence for $\mathrm{Au}^{\mathrm{III}}$ in gold exchanged Y1 samples.

From Fig. 1, it can be found that the first peaks (at $125^{\circ} \mathrm{C}$ ) of spectra $b-d$ were sharp and symmetric. All of these first peaks had broad shoulders at higher temperature $\left(190^{\circ} \mathrm{C}\right)$. These shoulders could be assigned to the reduction of large gold particles which were too large to exist inside the cavities of the zeolite, and could deposit only on the outer surface of the zeolite (because large particles generally show broader reduction peaks and higher reduction temperatures than ions and small clusters). To confirm this assignment, another reference sample, Au-16-2/ $\mathrm{Y} 1$, was prepared following procedures similar to those for Au-16/Y1; except no zeolite was added into the chloroauric acid solution, and the solution was filtered on $5 \mathrm{~g}$ of $\mathrm{Y} 1$ after being stirred at $80^{\circ} \mathrm{C}$ for $16 \mathrm{~h}$. The resulting Au-16-2/Y1 contained only 0.18 wt. $-\%$ of gold (much less than 1.59 wt.-\% on Au-16/Y1), and by TEM the average particle size was about one third of that on $\mathrm{Au}-16 / \mathrm{Y} 1$. Because $\mathrm{Y} 1$ was contacted with the gold solution only at short time periods of the filtration process 
for the preparation of Au-16-2/Y1, it is considered that almost all gold species on $\mathrm{Au}-16-2 / \mathrm{Y} 1$ were present as large particles (about $10 \mathrm{~nm}$ in diameter from TEM) and located right on the outer surface of Y1. Fig. 1e shows the TPR spectrum of $\mathrm{Au}-16-2 / \mathrm{Y} 1$. A reduction peak appears around $190^{\circ} \mathrm{C}$, which is in close range with the shoulders of spectra $b-d$ in Fig. 1. Therefore, the results clearly demonstrate that the broad shoulders at $190^{\circ} \mathrm{C}$ of spectra b-d were the reduction of large gold particles deposited on the outer surface of the zeolite.

Based on the total peak areas under spectra b-d in Fig. 1, it could be calculated that the shoulders from the reduction of the large gold particles deposited on the outer surface of the zeolite contained only 14,19 and $21 \%$ of the loaded gold in $\mathrm{Au}-13 / \mathrm{Y} 1, \mathrm{Au}-16 / \mathrm{Y} 1$ and $\mathrm{Au}-10 / \mathrm{Y} 1$, respectively. This further confirmed that most of the loaded gold species existed inside the cavities of $\mathrm{Y}$-type zeolite, and the dispersion of gold in these exchanged catalysts was high.

From the above results, the formation of large gold particles deposited on the outer surface of gold-exchanged $\mathrm{Y}$-type zeolite was demonstrated. It seems that when the $\mathrm{pH}$ of the aqueous solution of chloroauric acid is increased by sodium hydroxide, gold( III) clusters are formed in the solution. If there is no suitable solid surface for deposition, these clusters will gradually combine to form precipitates. However, if they deposit on the zeolite surface, the clusters may coalesce (depending on the distance between them) to form large particles, as observed on exchanged $\mathrm{Au}-16 / \mathrm{Y} 1$ by TEM. By comparing the average diameter of gold particles of Au$16 / \mathrm{Y} 1$ with that of $\mathrm{Au}-16 / \mathrm{Y} 2$, it is found that the gold particle size on $\mathrm{Y}$-type zeolites is positively influenced by the number of ion exchange sites on zeolites. This suggests that the gold ions which were ion exchanged onto the outer surface of Y-type zeolite may play the role of nuclei for further deposition of gold(III) clusters from solution onto the zeolite. Subsequently, because the average distance between the neighboring ion exchange sites on Y1 is much shorter than on Y2, the clusters which were attached on the exchanged gold ions were easier to coagulate on Y1 than on Y2. As a result, the gold particle size on Au-16/Y1 was larger than that on $\mathrm{Au}-16 / \mathrm{Y} 2$.

From Table 1, it is found that the gold loading on Y 1 decreased but gold particle size increased with increasing amount of sodium hydroxide added to the chloroauric acid solution. This could be because there were larger and more gold(III) clusters formed in the solution, and therefore less gold ions were available for the cation exchange, which caused the decrease of gold loading in zeolite and the deposition of larger gold clusters on the outer surface of the zeolite.

\subsection{Catalytic activities of gold/Y catalysts}

The catalytic activities of Au-13/Y1, Au-16/Y1 and Au-10/Y1 for carbon monoxide oxidation are shown in Fig. 2. It is noticed that because the carbon balance between the inlet and outlet gases was maintained and did not change with the time-on-stream, the initial high conversion of carbon monoxide in Fig. 2 was 


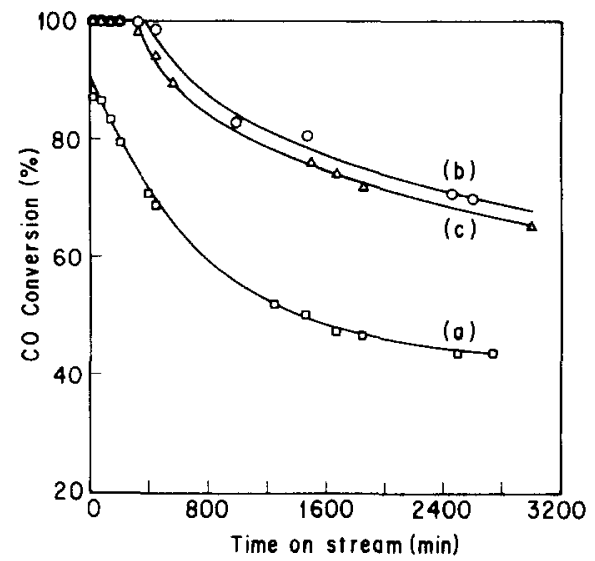

Fig. 2. Carbon monoxide conversion vs. time on stream at $30^{\circ} \mathrm{C}$ over as-prepared gold catalysts which contained $0.00162 \mathrm{~g}$ of Au. (a) Au-13/Yl, (b) Au-16/Y1, (c) Au-10/Y1.

not considered to come from the adsorption of carbon monoxide and carbon dioxide on the catalyst. It can be observed that although these gold catalysts possessed high activity without any pretreatment, they became deactivated during the experiment. The deactivated catalysts could not be regenerated by thermal treatment at $200^{\circ} \mathrm{C}$ in an air or a nitrogen flow, and even worse, they lost their activity further after thermal treatment. It has been reported in our previous work [21] that the deactivation of gold/Y during the activity test was attributed to the transformation of active gold( III) species into gold metal of poor activity. The further loss in activity after thermal treatment was also ascribed to the same reason as above. Besides, Knell et al. [22] reported that the deactivation of $\mathrm{Au} / \mathrm{ZrO}_{2}$ in the presence of excess oxygen was due to the progressive covering of the actives sites by oxygenated carbon species. Because the reaction conditions applied in the present work were also highly oxidative, the type of deactivation reported by Knell et al. cannot be excluded.

Although Au-13/Y1 also had a good activity without any pretreatment, its activity was the poorest among the three catalysts in Fig. 2. It is reported [2,23] that chlorine can poison carbon monoxide oxidation catalysts. Using extended Hückel calculations, it is found [24] that the existence of chlorine results in a significant energy shift of the oxygen dissociation curves toward higher energies, thus inhibiting the chemisorption of oxygen and its dissociation. Consequently, a loss in oxidation activity occurs. In the present study, because the amount of sodium hydroxide added in the preparation of $\mathrm{Au}-13 / \mathrm{Y} 1$ was the lowest of the three catalysts in Fig. 2, less $\mathrm{OH}^{-}$could substitute the chloride of chloroauric acid in the solution. By SEM-EDX, trace chloride was detected on Au-13/Y1, but no chloride on $\mathrm{Au}-16 / \mathrm{Y} 1$ or $\mathrm{Au}-10 / \mathrm{Y} 1$ was found. Therefore, the lower catalytic activity of Au-13/Y1 was ascribed to the presence of chloride.

\section{Conclusions}

Gold Y-type zeolite catalysts were prepared mainly by ion exchange. Although the amount of gold used for carbon monoxide oxidation in this study was one 
seventh of that in the work of Haruta et al. [1,2], high conversions could also be achieved without any pretreatment. The addition of sodium hydroxide into the preparation solution promoted the activity of the exchanged gold/Y catalyst. This was attributed to the substitution of hydroxide for the chloride around the gold ions. On the other hand, due to the transformation of active gold(III) species into gold metal of poor activity, the gold catalysts gradually lost their activities.

\section{Acknowledgements}

The authors thank Mr. Chih-Yang Hsiao for doing part of the literature search. The financial support from Cho Chang Tsung Foundation of Education in Taipei (Taiwan, R.O.C.) is highly appreciated.

\section{References}

[1] M. Haruta, T. Kobabyshi, H. Sano and N. Yamada, Chem. Lett., (1987) 405-408.

[2] M. Haruta, N. Yamada, T. Kobayashi and S. Iijima, J. Catal., 115 (1989) 301.

[3] M. Haruta, T. Takase, T. Kobayashi and S. Tsubota, in S. Yoshida, N. Takezawa and T. Ono (Editors), Catal. Sci. Tech., Vol. I, Kodansha, Tokyo, 1990, p. 331.

[4] M. Haruta, S. Tsubota, T. Kobayashi, H. Kageyama, M.J. Genet, and B. Delmon, J. Catal., 144 (1993) 175192.

[5] K. Torigoe and K. Esumi, Langmuir, 8 (1992) 59-63.

[6] D.G. Duff, A. Baiker and P.P. Edwards, Langmuir, 9 (1993) 2301-2309.

[7] S. Qiu, R. Ohnishi and M. Ichikawa, J. Chem. Soc., Chem. Commun., (1992) 1425.

[8] T. Itoh, M. Demura, M. Abe and Y. Tamaura, J. Appl. Phys., 69 (8) (1991) 4913.

[9] A.T. Bell, in L.L. Hegedus (Editor), Catalyst Design: Progress and Perspectives, Wiley, New York, 1987. pp. 103-140.

[10] Y.-M. Kang and B.-Z. Wan, Appl. Catal. A, 114 (1994) 35-49.

[11] V.I. Fedoseeva and G.V. Zvonareva, Geokhimiya, 10 (1987) 1486-1489.

[12] B.M. Mitsyuk, A.G. Mironov, A.M. Plyusnin, N.V. Belomestnova, N.K. Shirinbekov and N.P. Semenenko, Dokl. Akad. Nauk. SSSR, 306 (2) (1989) 452-455 [Geochem].

[13] F. Farges, J.A. Sharps and G.E. Brown, Geochim. Cosmochim. Acta, 57 (6) (1993) 1243-1252.

[14] Y.L. Lam and M. Boudart, J. Catal., 50 (1977) 530-540.

[15] M. Boudart and G. Meitzner, Springer Proc. Phys., Vol. 2 (EXAFS Near Edge Struct. 3), 1984, pp. $217-$ 221.

[16] Y.-M. Kang and B.-Z. Wan, unpublished data.

[17] C.N. Satterfield, Hetergeneous Catalysis in Industrial Practice, 2nd Ed., McGraw-Hill, Inc., 1991, Chapter 7.

[18] M.S. Tzou, B.K. Teo and W.M.H. Sachtler, J. Catal., 113 (1988) 220-235.

[19] Y.-M. Kang and B.-Z. Wan, Proceeding of the 11th R.O.C. Symposium on Catalysis and Reaction Engineering, Taipei, Taiwan, 26 Jun. 1993, p. 171.

[20] M. Haruta, H. Kageyama, N. Kamijo, T. Kobayashi and F. Delannay, Stud. Surf. Sci. Catal., 44 ( 1988 ) 33.

[21] Y.-M. Kang, and B.-Z. Wan, in preparation.

[22] A. Knell, P. Barnickel, A. Baiker and A. Wokaun, J. Catal., 137 ( 1992) 306-321.

[23] S.D. Lin, M. Bollinger and M.A. Vannice, Catal. Lett., 17 (1993) 245-262.

[24] T. Halachev and E. Ruckenstein, J. Catal., 73 (1982) 171-186. 